\title{
INHIBITORY EFFECT OF ETHANOLIC EXTRACT OF ERIOBOTRYA JAPONICA LEAVES PRE-INCUBATED WITH THEOPHYLLINE AND ASPIRIN ON ISOLATED GUINEA PIG TRACHEAL
}

\author{
MARIANNE*, URIP HARAHAP, EMIL SALIM, DADANG IRFAN HUSORI, FAHRUMSYAH JALI RAMBE, \\ NONI KRISTIANI
}

Department of Pharmacology Pharmacy, Faculty of Pharmacy, Universitas Sumatera Utara, Padang Bulan, Medan 20155, Indonesia. Email: marianne80@usu.ac.id

Received: 07 March 2018, Revised and Accepted:25 March 2018

ABSTRACT

Objectives: The objectives of the study were to examine the inhibitory effect of ethanol extract of Eriobotrya japonica leaves (EEEJL) pre-incubated with theophylline and aspirin on isolated guinea pig tracheal chains against acetylcholine (ACh)-induced contraction.

Methods: The effect of EEEJL (1-8 mg/Ml) on the isolated tracheal strips was tested in vitro. Furthermore, the mechanism of relaxant effects of EEEJL was evaluated in the presence of theophylline and aspirin.

Results: The contractile response evoked by Ach $\left(1.25 \times 10^{-3} \mathrm{M}\right)$ was decreased by EEEJL (effective concentration $\left.{ }_{50}=1.36 \mathrm{mg} / \mathrm{mL}\right)$ and has no significant difference of relaxant effect to that of EEEJL pre-incubated with theophylline and aspirin ( $p>0.05)$.

Conclusion: The EEEJL decreased the ACh-induced contraction through the inhibition of PDE and the protective effect on prostaglandin E2.

Keywords: Eriobotrya japonica, Biwa, ACh-muscarinic-3 receptor, Theophylline, Aspirin.

(C) 2018 The Authors. Published by Innovare Academic Sciences Pvt Ltd. This is an open access article under the CC BY license (http://creativecommons. org/licenses/by/4. 0/) DOI: http://dx.doi.org/10.22159/ajpcr.2018.v11s1.26565

\section{INTRODUCTION}

Asthma is a chronic airway inflammatory disease characterized by obstruction, hyperresponsiveness, and remodeling of airway [1]. It is considered as a serious health problem and represents a major cause of public health in both developed and developing countries. According to the World Health Organization, there are around 300 million annual cases of asthma worldwide. The incidence of asthma has scaled dramatically, despite increased use of medications that suppress airway inflammation and repress contraction of smooth muscle that surrounds the airways. Asthmatic patients display episodes of airway inflammation that potentiates reversible airway smooth muscle contraction [2]. Recent pharmacological management for controlling asthma is mainly based on corticoids as anti-inflammatory agents in combination with $\beta 2$-adrenergic agonists as bronchodilators [3]. However, there is an increasing demand for finding new medicines in asthma therapy, as these drugs cause serious side effects.

Natural products offer a remarkable pharmacological perspective for drug development relating to their widespread acceptability and broadspectrum activities. Hence, it is valuable to search for effective medicines for treating asthma using plant resources. Folium eriobotryae (FE), the dry leaf of Eriobotrya japonica (Thunb.) Lindl. (Rosaceae), commonly known as Biwa in Indonesia, has been used traditionally to treat diseases of the respiratory system, cough, chronic bronchitis, inflammation, and diabetes. In addition, this plant is also useful to treat diarrhea, stress relievers, cholesterol, nicotine neutralizer, pain reliever, and to smooth the skin. FE has several other biological activities such as anti-diabetes [4], neuroprotective [5], antioxidant [6], and anticancer effects [7]. In the previous studies, FE was demonstrated to exert a noticeable effect on ovalbumin-induced asthma [8] and relieve the symptoms of chronic bronchitis rats [9]. The phytochemical studies on FE shown the presence of various triterpenes, flavonoids, sesquiterpenes, and tannins [10,11]. Nevertheless, despite the many studies performed on the biological effects of FE, there are no scientific data about its bronchodilatory effects. Therefore, the present study aimed to investigate the pharmacological action and possible mechanisms of the ethanol extract of FE isolated tracheal strips.

\section{METHODS}

\section{Plant and extracts}

E. japonica leaves were collected from Simalem Resort garden, Merek, Sidikalang, North Sumatera, and dried at room temperature in the absence of sunlight. The plant was identified by botanists in the Herbarium Medanense, Universitas Sumatera Utara; the specimen number of the plant is 1443/MEDA/2017.

The ethanol extract was prepared as follows: $500 \mathrm{~g}$ of the chopped, dried plant was macerated with $300 \mathrm{~mL}$ ethanol for $48 \mathrm{~h}$. The solvent of the extract was then removed under reduced pressure until the extract volumes reached $20 \mathrm{~mL}$. Plant ingredient concentration in the final extract was $14.74 \mathrm{~W} / \mathrm{W}$.

\section{Tissue preparations}

Guinea pigs (300-400 g) were killed by cervical dislocation, and the tracheas were removed. Each trachea was cut into 10 rings (each containing 2-3 cartilaginous rings). All the rings were then cut open opposite the trachealis muscle and sutured together to form a tracheal chain.

Tissue was then suspended in a $40 \mathrm{~mL}$ organ bath (organ bath PowerLab, ML0146/50 PanLab, AD Instrument, New Zealand) containing Krebs solution of the following composition: $\mathrm{NaC} 15.9 \mathrm{~g}$, $\mathrm{NaHCO}_{3} 2.1 \mathrm{~g}, \mathrm{MgSO}_{4} 0.11 \mathrm{~g}, \mathrm{KH}_{2} \mathrm{PO}_{4} 0.16 \mathrm{~g}, \mathrm{KC} 10.35 \mathrm{~g}$, and glucose $2.0 \mathrm{~g}$, these compounds were dissolved in $1 \mathrm{~mL}$ of distilled water. The Krebs solution was maintained at $37^{\circ} \mathrm{C}$ and gassed with $95 \% \mathrm{O}_{2}$ and $5 \% \mathrm{CO}_{2}$. Tissue was allowed to equilibrate for at least $45 \mathrm{~min}$ [12].

\section{Protocols}

Effective concentration ( $\left.E C_{80}\right)$ acetylcholine testing on tracheal smooth muscle

$\mathrm{EC}_{80}$ of ACh to contract tracheal smooth muscle was determined. Then, this concentration would be used to contract the muscle before the extract. Measurements of contraction were performed on a graded 
basis by giving a series of acetylcholine (ACh) concentrations of $10^{-8}-3 \times 10^{-3} \mathrm{M}$. Tracheal marmots which had been forty-brated for $45 \mathrm{~min}$ (with alternation of Kreb's solution every $15 \mathrm{~min}$ for 3 times) were given $\mathrm{ACh}$ chloride solution with the concentrations of $10^{-8}-3 \times 10^{-3} \mathrm{M}$ (smooth tracheal muscle of marmots shows maximum contraction response). The smooth muscle contraction of tracheal marmots that occurred was recorded on the recorder. In this experiment, the effect of eight cumulative concentrations from the extract was examined; the effect of the extract pre-incubated with theophylline and aspirin was also measured to investigate the possible mechanism. A decrease in tone was considered as an inhibitory effect and expressed as positive percentage change in proportion to maximum contraction obtained due to contractile agents. The study was approved by the Animal Research Ethic Committee, Faculty of Mathematics and Natural Sciences, Universitas Sumatera Utara.

\section{Statistical analysis}

The data of the inhibitory effect of different experiments were expressed as mean \pm SEM. The graph patterns of effect of ethanol extract of Eriobotrya japonica leaves (EEEJL) in the absence and presence of theophylline and aspirin were compared using independent t-test. Significance was accepted at $\mathrm{p}<0.05$.

\section{RESULTS}

\section{Phytochemical screening}

The phytochemical analysis conducted on E. japonica extract revealed the presence of flavonoids, tannins, glycosides, saponins, and steroids/ triterpenoids (Table 1). These phytochemical compounds are known to support bioactive activities in medicinal plants and thus responsible for the relaxant effect of the plant extract used in this study.

\section{Effect of ethanol extract of $E$. japonica on isolated tracheal strips} Series concentration of Ach $\left(10^{-8}-3 \times 10^{-3} \mathrm{M}\right)$ was applied on isolated tracheal strips to obtain $\mathrm{EC}_{80}$; this concentration will be used to induce contraction. Fig. 1 showed that percentage contraction of tracheal smooth muscle increased with the addition of ACh concentration. The maximum ACh concentration for tracheal smooth muscle contraction was $3 \times 10^{-3} \mathrm{M}$. The next given concentration did not change the percentage of smooth muscle contraction. $\mathrm{EC}_{80}$ of $\mathrm{ACh}$ was $1.25 \times$ $10^{-3} \mathrm{M}$.

It can be seen that EEEJL $(1-8 \mathrm{mg} / \mathrm{mL})$ relaxed the isolated tracheal strips pre-incubated with ACh (Fig. 2). EEEJL $1 \mathrm{mg} / \mathrm{mL}$ relaxed the isolated organ as much as $59 \%$. The following cumulative concentrations of EEEJL showed significant increase reaching 80, 98 , and $116 \%$ at concentration of 2,3 , and $4 \mathrm{mg} / \mathrm{mL}$, respectively. The next cumulative concentrations at $5-8 \mathrm{mg} / \mathrm{mL}$ did not show significant increases. EEEJL was effective to relax the isolated organ with $\mathrm{EC}_{50} 1.36 \mathrm{mg} / \mathrm{mL}$.

To investigate the possible mechanism of EEEJL on the inhibition of PDE, the relaxation effect of EEEJL pre-incubated with theophylline was tested. Fig. 3 shows that no significant difference between EEEJL and EEEJL pre-incubated with theophylline ( $p>0.05)$.

Table 1: The phytochemical components of E. japonica based on the preliminary ethanol crude leaf extract screening

\begin{tabular}{ll}
\hline Phytochemical compounds & Presence \\
Alkaloid & - \\
Flavonoids & + \\
Tannins & + \\
Glycosides & + \\
Saponins & + \\
Steroids/triterpenoids & + \\
+: Present, -: Absent & \\
\hline
\end{tabular}

Furthermore, to explore the possible mechanism of EEEJL on COX, the relaxation effect of EEEJL pre-incubated with aspirin was carried out. Fig. 4 shows that no significant difference between EEEJL and EEEJL pre-incubated with aspirin ( $p>0.05)$.

\section{DISCUSSION}

In the present research, EEEJL induced relaxation precontracted by ACh on tracheal strips. This effect may be due to the role of its chemical content. The phytochemical screening showed that this extract contains varied kinds of compounds, namely: Flavonoids, tannins, glycosides, saponins, and steroids/triterpenoids. These chemical constituents, which are also present in many other plants, relaxed bronchus through their inhibition on ACh and histamine [13]. To assess the extract mechanism as a bronchodilator, specifically its possibility in the inhibition of PDE and COX, EEEJL was pre-incubated with theophylline, a PDE inhibitor, and aspirin, a COX inhibitor, before being contracted. The results showed that theophylline and aspirin did not modify the pattern of the relaxation graphs, it can be seen that the EEEJL graph pre-incubated with theophylline and aspirin did not have significant difference compared to that of without theophylline and aspirin. These results suggested that bronchodilator effects of this extract were related to the inhibition of PDE and this extract avoided the damage of prostaglandin E2 (PGE2). Theophylline acts as a bronchodilator through its mechanism in the inhibition of PDE [14], whereas, aspirin could cause bronchoconstriction by its inhibitory effect on COX, which leading to the decrease of PGE2, a lung protector [15]. These inhibitions

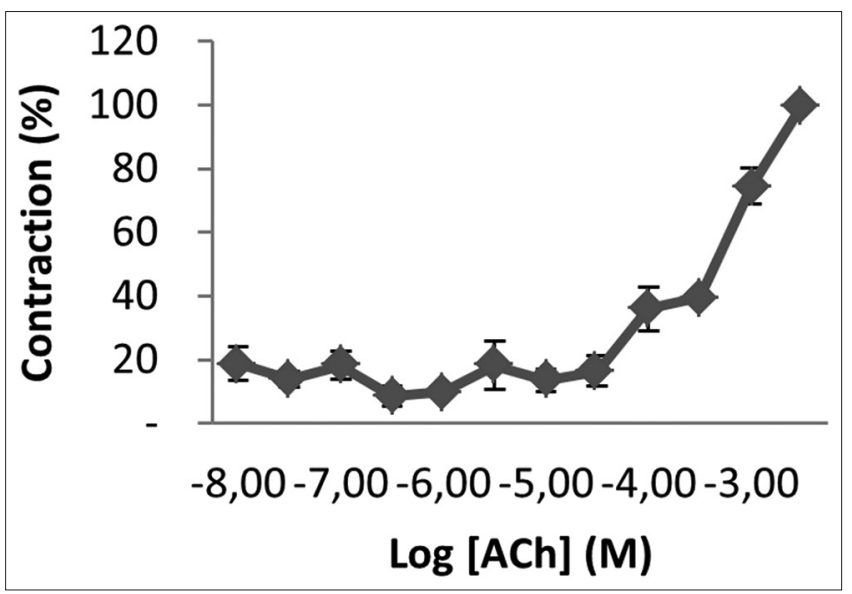

Fig. 1: Effect of acetylcholine $\left(10^{-8}-3.10^{-3} \mathrm{M}\right)$ on isolated tracheal strips $(n=4)$

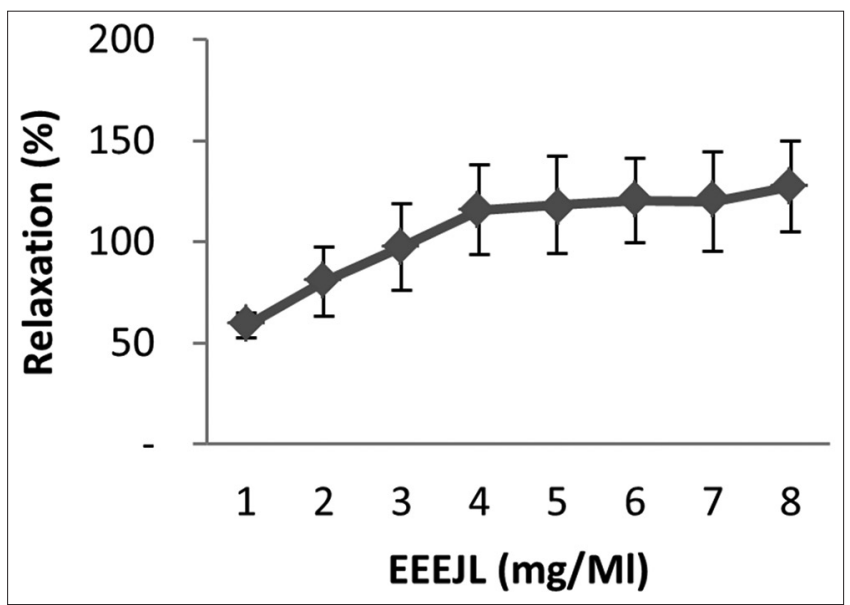

Fig. 2: Effect of ethanol extract of Eriobotrya japonica leaves (1-8 $\mathrm{mg} / \mathrm{mL}$ ) on isolated tracheal strips pre-incubated with acetylcholine 


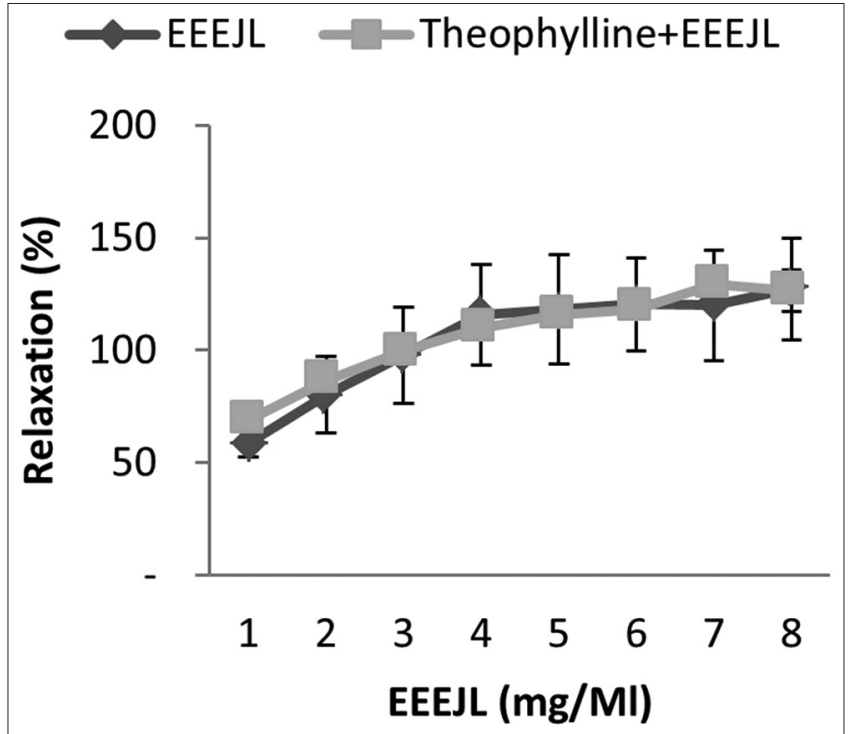

Fig. 3: Effect of ethanol extract of Eriobotrya japonica leaves (EEEJL) (1-8 mg/mL) pre-incubated with acetylcholine (Ach) and

EEEJL (1-8 $\mathrm{mg} / \mathrm{mL})$ pre-incubated with ACh and theophylline on isolated tracheal strips. Symbols and vertical bars represent means and SEM $(n=5)$. The similarity of both graphs patterns was analyzed using independent t-test

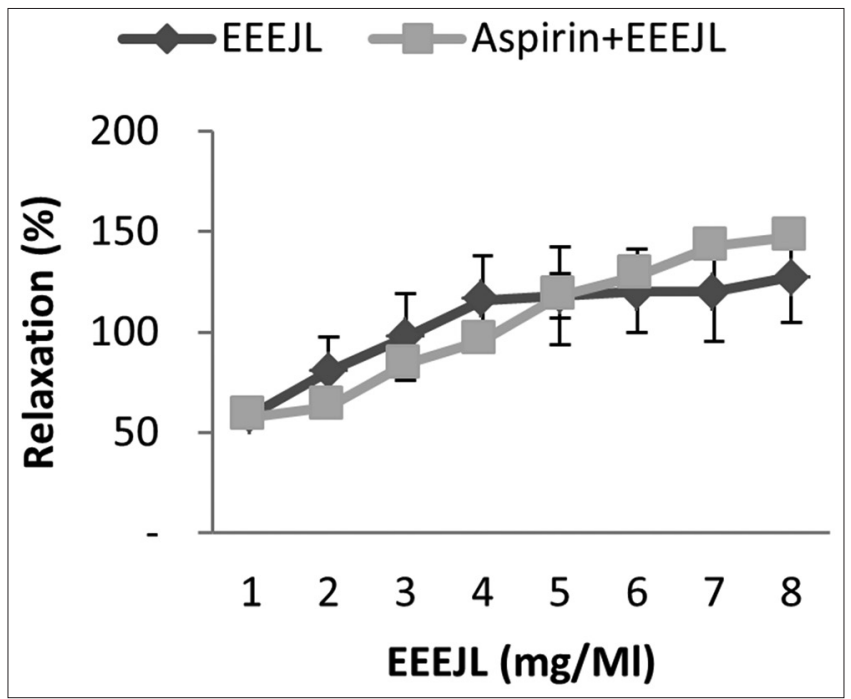

Fig. 4: Effect of ethanol extract of Eriobotrya japonica leaves (EEEJL) (1-8 mg/mL) pre-incubated with acetylcholine (Ach) and EEEJL (1-8 $\mathrm{mg} / \mathrm{mL})$ pre-incubated with ACh and aspirin on

isolated tracheal strips. Symbols and vertical bars represent means and SEM $(n=5)$. The similarity of both graphs patterns was analyzed using independent t-test

may be contributed by the presence of flavonoids, tannins, glycosides, saponins, and steroids/triterpenoids in the extract.

\section{CONCLUSION}

The results suggest that EEEJL induces relaxation in isolated tracheal strips through the inhibition of PDE and the protective effect on PGE2.

\section{ACKNOWLEDGMENT}

This study was financed by non PNBP fund of Universitas Sumatera Utara year 2017, according to the letter of assignment agreement number: 5338/UN5.1.R/PPM/2017 about TALENTA research.

\section{CONFLICT OF INTEREST}

The authors have no conflict of interest in this research.

\section{REFERENCES}

1. Bousquet J, Jeffery PK, Busse WW, Johnson M, Vignola AM. Asthma: From bronchoconstriction to airways inflammation and remodeling. Am J Respir Crit Care Med 2000;161:1720-45.

2. Khan M, Shah AJ, Gilani AH. Insight into the bronchodilator activity of Vitex negundo. Pharm Biol 2015;53:340-4

3. Chung KF, Caramori G, Adcock IM. Inhaled corticosteroids as combination therapy with $\beta$-adrenergic agonists in airways disease: Present and future. Eur J Clin Pharmacol 2009;65:853-71.

4. Li WL, Wu JL, Ren BR, Chen J, Lu CG. Pharmacological studies on anti-hyperglycemic effect of folium eriobotryae. Am J Chin med 2007;35:705-11.

5. Kim MJ, Lee J, Seong AR, Lee YH, Kim YJ, Baek HY, et al. Neuroprotective effects of Eriobotrya japonica against $\beta$-amyloidinduced oxidative stress and memory impairment. Food Chem Toxicol 2011;49:780-4

6. Bae D, You Y, Yoon HG, Kim K, Lee YH, Kim Y, et al. Protective effects of loquat (Eriobotrya japonica) leaves against ethanol-induced toxicity in HepG2 cells transfected with CYP2E1. Food Sci Biotechnol 2010;19:1093-6.

7. Ito $\mathrm{H}$, Kobayashi $\mathrm{E}$, Li SH, Hatano $\mathrm{T}$, Sugita $\mathrm{D}$, Kubo $\mathrm{N}$, et al. Antitumor activity of compounds isolated from leaves of Eriobotrya japonica. J Agric Food Chem 2002;50:2400-3.

8. Jung JY, Yim YK, Lee H. The Effects of eriobotryae folium herbalacupuncture at ST36 on ovalbumin-induced asthma in C57BL mouse. Korean J Acupunct 2005;22:91-107.

9. Huang Y, Li J, Cao Q, Yu SC, Lv XW, Jin Y, et al. Anti-oxidative effect of triterpene acids of Eriobotrya japonica (Thunb.) lindl. leaf in chronic bronchitis rats. Life Sci 2006;78:2749-57.

10. Ferreres F, Gomes D, Valentão P, Gonçalves R, Pio R, Chagas EA, et al. Improved loquat (Eriobotrya japonica Lindl.) cultivars: Variation of phenolics and antioxidative potential. Food Chem 2009;114:1019-27.

11. Tan H, Ashour A, Katakura Y, Shimizu K. A structure-activity relationship study on antiosteoclastogenesis effect of triterpenoids from the leaves of loquat (Eriobotrya japonica). Phytomedicine 2015;22:498-503.

12. Harahap U, Husori DI, Yuliasmi S, Patilaya P, Laila L, Prasetyo BE, et al. Inhibitory effect of ethanolic extract of Curanga felterrae pugun tano leaves on acetylcholine muscarinic3 receptors induced on isolated guinea pig tracheal. Asian J Pharm Clin Res 2017;10:95-8.

13. Kale RN, Patil RN, Patil RY. Asthma and herbal drugs. Pathophysiology 2010;20:4

14. Rabe KF, Magnussen H, Dent G. Theophylline and selective PDE inhibitors as bronchodilators and smooth muscle relaxants. Eur Respir J 1995;8:637-42.

15. Picado C. Aspirin-intolerant asthma: Role of cyclo-oxygenase enzymes. Allergy 2002;57:58-60. 